\title{
Determination of Ambroxol in an Automated Multi-Pumping Pulsed Flow System
}

\author{
João L. M. Santos, ${ }^{* \dagger}$ Arnaud Clausse, ${ }^{* *}$ José L. F. C. Lima,* M. L. M. F. S. Saraiva, \\ and António O. S. RANGEL ${ }^{* * *}$ \\ * REQUIMTE, Departamento de Química-Fisica, Faculdade de Farmácia, Universidade do Porto, \\ Rua Anibal Cunha 164, 4050-047 Porto, Portugal \\ **Ecole Nationale Supérieure de Chimie de Clermont-Ferrand, 24 avenue des Landais, \\ BP 187, 63174 Aubière Cedex, France \\ ***Escola Superior de Biotecnologia, Universidade Católica Portuguesa Rua António Bernardino de Almeida, \\ 4200-072 Porto, Portugal
}

\begin{abstract}
A new flow methodology exploiting the multi-pumping approach was developed for the spectrophotometric determination of ambroxol hydrochloride in pharmaceutical preparations. The flow manifold was implemented by using, exclusively, multiple solenoid-actuated micro-pumps, which acted simultaneously as sample insertion, solutions propelling and reagents commutation units. Linear calibration plots were obtained over an ambroxol concentration ranging from 10 to $200 \mathrm{mg} \mathrm{l}^{-1}$ (r.s.d. $<0.5 \%, n=15$ ) and a sampling rate of about 60 samples per hour (flow rate $=1.92$

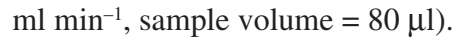

(Received July 12, 2004; Accepted November 22, 2004)

\section{Introduction}

Ambroxol hydrochloride, 2-amino-3,5-dibromo- $\mathrm{N}$-[trans-4hydroxycyclohexyl]benzylamine hydrochloride (Fig. 1), is a therapeutic agent that is used in a variety of respiratory disorders including chronic bronchitis and infant respiratory distress syndrome. ${ }^{1}$ Most of the proposed methodologies for ambroxol determination are based on chromatographic methods, mainly HPLC with UV detection, ${ }^{2-4}$ gas chromatography, voltammetry $^{6}$ and capillary isotachophoresis. ${ }^{7}$ The reference procedure of the Portuguese Pharmacopoeia ${ }^{8}$ is based on a potentiometric titration.

Continuous flow methodologies have in recent years played a fundamental role in the search for new automated analytical approaches; such ways have become the supporting foundation for innovative deployments in terms of sample handling and processing. ${ }^{9-12}$ The newest multi-pumping flow systems ${ }^{13}$ were intended to be a constructive automation tool adding functionality and simplicity to continuous flow methodologies; such systems are easily assembled with a minimum of parts and can be straightforwardly adjusted and operated under computer control.

The main purpose of this work was to develop a simple, fast and low-cost automated procedure for spectrophotometric determination of ambroxol hydrochloride in pharmaceutical preparations using $p$-dimethylaminobenzaldehyde (PDBA) as the color-forming reagent. The main advantages of the described method arose from the exploitation of the analytical potential of the multi-pumping flow system: the utilization of

$\dagger$ To whom correspondence should be addressed.

E-mail: joaolms@ff.up.pt inexpensive instrumentation and materials, ease of operation and versatility, high sampling frequency and decrease of sample and reagent consumption.

\section{Experimental}

\section{Reagents}

A $200 \mathrm{mg}^{-1}$ ambroxol hydrochloride (Sigma) standard solution was prepared in $1.8 \mathrm{~mol} \mathrm{l}^{-1} \mathrm{HCl}$. This stock solution was maintained under refrigeration at $5^{\circ} \mathrm{C}$. Working standards were daily prepared by appropriate dilutions with the same $\mathrm{HCl}$ solution.

A $0.2 \mathrm{~mol} \mathrm{l}^{-1}$ PDBA (Sigma) solution was prepared daily in $1.8 \mathrm{~mol} \mathrm{l}^{-1} \mathrm{HCl}$. This solution was maintained under protection from light.

The analyzed pharmaceutical preparations of ambroxol hydrochloride were those commercially available in Portugal. Samples were prepared in $1.8 \mathrm{~mol} \mathrm{l}^{-1} \mathrm{HCl}$.

\section{Equipment}

The developed flow system consisted of three micro-pumps (Ref. 090SP-BIO-CHEM Valve Inc., Boonton, USA), flow lines

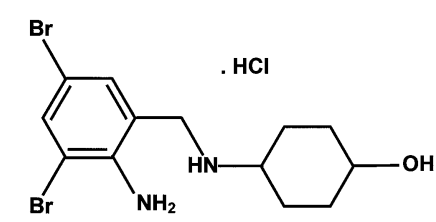

Fig. 1 Structure of ambroxol hydrochloride. 


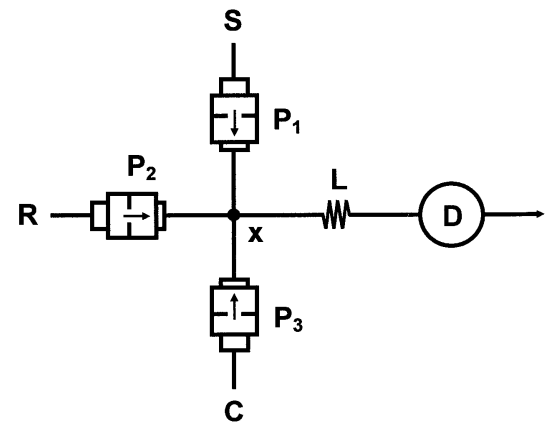

Fig. 2 Multi-pumping flow diagram: S, sample; R, $0.2 \mathrm{~mol} \mathrm{l}^{-1}$ PDBA reagent solution in $1.8 \mathrm{~mol} \mathrm{l}^{-1} \mathrm{HCl} ; \mathrm{C}, 1.8 \mathrm{~mol} \mathrm{l}^{-1} \mathrm{HCl}$ carrier solution; $\mathrm{L}$, reactor $(30 \mathrm{~cm}) ; \mathrm{P}_{1}, \mathrm{P}_{2}$ and $\mathrm{P}_{3}$, solenoid micro-pumps; $\mathrm{x}$, confluence point; $\mathrm{D}$, detector $(413 \mathrm{~nm})$.

(including a reaction coil) made from 0.8 -mm i.d. PTFE tubing, a LaboMed Model Spectro 22RS spectrophotometer $(\lambda=413$ $\mathrm{nm})$, a home-made confluence point, end-fittings and connectors. The micro-pumps were of the fixed displacement diaphragm type, being solenoid operated and dispensing $8 \mu \mathrm{l}$ per stroke. The spectrophotometer was equipped with a $70-\mu \mathrm{l}$ inner volume (10-mm optical path) flow-cell. Data acquisition and system control were accomplished by means of a Pentium I based microcomputer equipped with a PC-LABCard Model PCL-711B interface card from Advantech. The software was developed in Quick-basic 4.5 and permitted to control the solenoid micro-pumps and real-time data processing. A CoolDrive (NResearch Inc., New Jersey, USA) power drive was used to operate the solenoid micro-pumps.

\section{Multi-pumping flow manifold}

The flow diagram pictured in Fig. 2 and represents the three solenoid micro-pumps $\mathrm{P}_{1}, \mathrm{P}_{2}$ and $\mathrm{P}_{3}$ positioned around the $\mathrm{x}$ confluence connector. These micro-pumps are responsible for the insertion and propelling of the sample $\left(\mathrm{P}_{1}\right)$, reagent $\left(\mathrm{P}_{2}\right)$ and carrier $\left(\mathrm{P}_{3}\right)$ solutions, respectively, and no conventional valve for sample insertion is required.

The analytical cycle was started when the carrier solution (1.8 mol $1^{-1} \mathrm{HCl}$ ) was pumped by $\mathrm{P}_{3}$ at a fixed pulse frequency, which defined the flow rate for the $8-\mu 1$ stroke volume, in order to establish the baseline. Then $\mathrm{P}_{3}$ was switched off and the sample was inserted by actuation of $P_{1}$. The number of pulses plus the stroke volume $(8-\mu \mathrm{l})$ defined the whole sample volume. A similar situation occurs with the introduction of the reagent solution by means of $\mathrm{P}_{2}$. However, instead of inserting the sample followed by the adding of PDBA, we have used a distinct approach consisting of the alternate actuation of $\mathrm{P}_{1}$ and $\mathrm{P}_{2}$ which allowed intercalating small sample volumes with small reagent volumes. This way a tandem stream consisting of neighboring slugs of sample and reagent solutions is established inside the main channel. These slugs underwent faster intermixing as the entire processed sample zone was transported by means of $\mathrm{P}_{3}$ (while $\mathrm{P}_{1}$ and $\mathrm{P}_{2}$ were switched off) towards the detector where the formed products were monitored at $413 \mathrm{~nm}$. Although the analytical peaks are similar to those obtained with more conventional flow techniques, the pulsed nature of the flowing stream that is a consequence of the abrupt alteration of the solution movements upon actuation of the diaphragm micropump is easily perceptible in the stair-like peak profile visible at increased recording speed (Fig. 3).

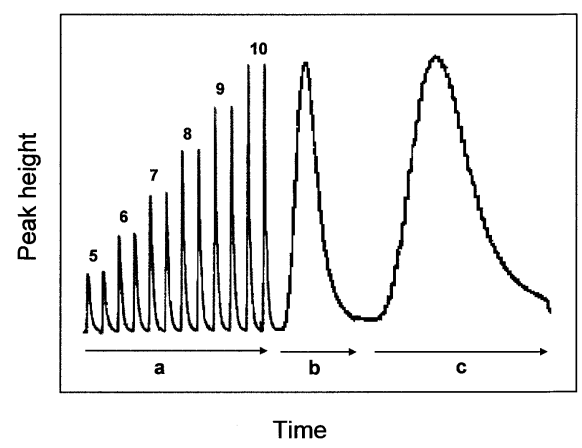

Fig. 3 Typical analytical signals (by using increasing number of sample pulses -5 to 10 pulses) showing the stair-like profile. The

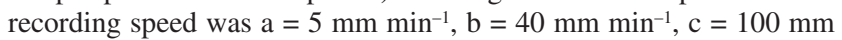
$\min ^{-1}$.

\section{Results and Discussion}

Preliminary experiments revealed that the reaction of ambroxol with PDBA in acidic medium was fast. A general continuous flow system principle states that the obtained analytical signal is the result of two combining processes: the physical sample/reagent mutual dispersion and the rate of formation of the measured chemical reaction products. ${ }^{9}$ In this sense, if the chemical reaction is fast enough and does not impair detection, then the sample residence time has to be restricted to the minimum necessary to ensure adequate sample/reagent homogenization and thus the highest degree of reaction completion prior to detection, guaranteeing that dispersion does not result in a loss of sensitivity. Since the pulsed nature of the newly proposed multi-pumping flow systems (MPFS $)^{13}$ guarantees prompt sample and reagent mixing we are assured of a fast reaction zone homogenization and enhanced reaction development. Another important advantage of multi-pumping systems is that they behave as multi-channel FIA systems because the reagent solutions are equally added to all zones of the sample plug, surpassing the limited sample/reagent intermixing of typical single-line FIA system, but at the same time they assure an effective control of the added volumes which could be precisely focused on the sample plug, thus avoiding superfluous reagents' consumption.

\section{Sample volume, sampling strategy and flow rate}

Since reaction rate was high, the optimization of the analytical procedure was primarily directed towards the attainment of high sampling rate, good reproducibility, low reagent consumption and a wide analytical concentration range. By using distinct reaction coils and a $1.92 \mathrm{ml} \mathrm{min}{ }^{-1}$ flow rate, we verified that the analytical signal increased with increasing sample pulses, reached an upper value that depended on the reactor's length, and then decreased. For 10 sample pulses $(80 \mu \mathrm{l})$, the highest analytical signal was obtained with a $30-\mathrm{cm}$ reactor, while with 20 sample pulses $(160 \mu \mathrm{l})$ the highest value was achieved with a longer $70-\mathrm{cm}$ coil. These results confirmed the great mixing capacity of the multi-pumping flow system. In fact, 10 sample pulses (representing $80 \mu \mathrm{l}$ of sample) that created a reaction zone of $160 \mu \mathrm{l}$ upon the addition of 10 pulses $(80 \mu \mathrm{l})$ of reagent were appropriately dispersed within just a $30-\mathrm{cm}$ reactor $(150$ $\mu \mathrm{l})$ and a $70 \mu \mathrm{l}$ flow-cell. Moreover, the residence time was merely $13 \mathrm{~s}$. Two complementary features, the multi-pumping characteristic pulsed flow pattern and the used sampling 
Table 1 Results obtained in the determination of ambroxol hydrochloride in pharmaceutical preparations

\begin{tabular}{|c|c|c|c|c|}
\hline \multirow[b]{2}{*}{ Sample } & \multirow{2}{*}{$\begin{array}{l}\text { Amount } \\
\text { declared }\end{array}$} & \multicolumn{2}{|c|}{ Amount found } & \multirow{2}{*}{$\begin{array}{r}\text { R.D. } \\
\%^{\mathrm{a}}\end{array}$} \\
\hline & & $\begin{array}{l}\text { Proposed } \\
\text { methodology }\end{array}$ & $\begin{array}{l}\text { Reference } \\
\text { methodology }\end{array}$ & \\
\hline $\begin{array}{l}\text { Drenoxol (syrup), } \\
\mathrm{mg} / 10 \mathrm{ml}\end{array}$ & 30 & $29.3 \pm 0.6$ & 28.7 & 2.1 \\
\hline $\begin{array}{l}\text { Mucosolvan } \\
\text { (injectable), } \\
\mathrm{mg} / 2 \mathrm{ml}\end{array}$ & 15 & $15.4 \pm 0.1$ & 14.7 & 4.7 \\
\hline $\begin{array}{l}\text { Broncoliber } \\
\text { (capsule), mg }\end{array}$ & 120 & $118.8 \pm 0.9$ & 115.4 & 2.9 \\
\hline $\begin{array}{l}\text { Bromax (syrup), } \\
\mathrm{mg} / 5 \mathrm{ml}\end{array}$ & 30 & $29.1 \pm 0.7$ & 30.4 & -4.3 \\
\hline $\begin{array}{l}\text { Benflux (tablet), } \\
\text { mg }\end{array}$ & 30 & $29.1 \pm 0.3$ & 28.6 & 1.7 \\
\hline
\end{tabular}

a. Relative deviation expressed in percentage of the developed methodology regarding the reference methodology.

strategy, explain this performance. In effect, sample zone homogenization is supported not only by radial or axial dispersion at the sample/reagent interfaces but is greatly enhanced by the chaotic movement of the solutions caused by the pulsed turbulent flow. On the other hand, the intercalation of multiple small sample and reagent pulses created multiple reaction interfaces that contribute to a faster reaction zone homogenization, improving sensitivity.

The analytical signals obtained with 10 sample pulses and a $30-\mathrm{cm}$ reaction coil, although slightly lower, were comparable to those obtained with longer coils and greater sample volumes, assuring at the same time an higher sampling rate and lower reagent consumption. Thus these parameters were selected for the posterior experiments.

In a multi-pumping flow system, the flow rate is controlled by programming adjustment and is determined by the pulse frequency plus micro-pump stroke volume. Flow rate was evaluated by using pulse frequencies of $60,80,120$ and 240 pulses $\mathrm{min}^{-1}$ that produced flow rates of about $0.480,0.640$, 0.960 and $1.92 \mathrm{ml} \mathrm{min}^{-1}$. It was verified that the analytical signal increased with the flow rate, confirming that, despite the reduced reaction coil and the high flow rate, a good sample/reagent intermixing and an adequate reaction completion are achieved prior to detection. Since a flow rate of $1.92 \mathrm{ml} \mathrm{min}^{-1}$ (240 pulses $\mathrm{min}^{-1}$ ) provided both adequate sampling rate and sensitivity, this was the value selected for the later experiments.

\section{Acid and PDBA concentration}

PDBA concentration and $\mathrm{HCl}$ concentration were also parameters affecting the magnitude of the analytical signal. We have noticed that the analytical signal increased with the acid concentration until $1.8 \mathrm{~mol} \mathrm{l}^{-1}$ and then slightly decreased. This pattern could be explained by either an increase in the viscosity that restrained sample dispersion and thus sample/reagent mixing or by a decrease in the reaction kinetics. The influence of PDBA was evaluated for concentrations ranging from 0.07 to $0.35 \mathrm{~mol} \mathrm{l}^{-1}$. The obtained results showed that the analytical signal increased steadily with the PDBA concentration until 0.2 mol $1^{-1}$ and then become stable. In view of the higher peaks obtained, $0.2 \mathrm{~mol}^{-1}$ PDBA was used in all subsequent experiments.

\section{Analysis of pharmaceutical preparations}

After system dimensioning, linear calibration plots for distinct sample volumes were obtained. As a compromise among sampling rate, concentration range, sensitivity, precision and accuracy, a sample volume of $80 \mu \mathrm{l}$ (10 pulses) was selected for carrying out the determination of ambroxol hydrochloride in distinct commercially available pharmaceutical formulations, enabling an analytical working range between 10 and $200 \mathrm{mg}$ $1^{-1}$. The operating conditions were the following: 10 pulses for sample insertion $(80 \mu \mathrm{L})$ intercalated with 10 pulses of $0.2 \mathrm{~mol}$ $1^{-1}$ PDBA solution, pulse frequency of $240 \mathrm{~min}^{-1}$ (corresponding to a flow rate of approximately $1.92 \mathrm{ml} \mathrm{min}^{-1}$ ) for the $1.8 \mathrm{~mol} \mathrm{l}^{-1}$ $\mathrm{HCl}$ carrier solution and $30-\mathrm{cm}$ reaction coil. Under these conditions, the calibration curve equation was $A=0.0482 C+$ 1.292 , where $A$ represents the peak height expressed in $\mathrm{cm}$ and $C$ represents the ambroxol hydrochloride concentration expressed in $\mathrm{mg} \mathrm{l}^{-1}$, with a correlation coefficient of 0.998 . The obtained results showed good agreement with those furnished by the reference procedure and complied with the declared dosage with a relative deviation (in percentage) from -4.3 to $4.7 \%$. These results were further confirmed by a Student $t$-test: the estimated $t$-value $(0.358)$ was lower than the tabulated one (2.57) for a confidence level of 95\% $(n=5)$. System performance showed a good reproducibility with a relative standard deviation of less than $0.5 \%(n=15)$. The evaluation of the interfering effect of several compounds used as excipients in the manufacturing of the pharmaceutical formulations (starch, glucose, sucrose, talc, magnesium stearate, methylcellulose, sodium benzoate and sodium citrate) showed that up to the maximum value assayed (100 molar ratio excipient/ambroxol) no interference was found. The developed flow system was very stable and no baseline drift has been found. Moreover, the analytical system showed a great robustness and the micropumps' performance remained unaffected throughout the entire work, even though they were operated at pulse frequencies close to their upper operational limiting value. The sampling throughput was about 60 samples per hour. Results of the ambroxol hydrochloride determinations are summarized in Table 1.

\section{Conclusions}

The obtained results showed that the developed analytical methodology could be considered a valuable alternative for the determination of ambroxol hydrochloride in pharmaceutical preparations, especially if one considers that most of the Pharmacopoeias do not refer to any particular procedure. The method combines a simple easily assembled modular configuration with a high degree of automation providing a very high sample throughput and low reagent consumption. Moreover, it is reliable, precise and accurate and, due to the micro-pumps robustness and extended lifetime, requires only minor maintenance. Solenoid micro-pumps, acting as the only working elements of the flow set-up, assure multi-pumping flow systems high operational versatility either in terms of the multiple tasks they could accomplish, like sample insertion, reagents addition and solutions propelling, or the distinct strategies that could be used to control the formation of the reaction zone and thus reaction development.

\section{Acknowledgements}

The authors are grateful for the financial support under the Agro 
Program (Project 273).

\section{References}

1. Martindale, "The Complete Drug Reference", 32nd ed., 1999, Pharmaceutical Press, London, 169.

2. M. Nobilis, J. Pastera, D. Svoboda, J. Kvetina, and K. Macek, J. Chromatogr. Biomed. Appl., 1992, 58, 251.

3. B. D. Kiss, K. B. Nemes, I. Urmos, J. Szunyog, and I. Klebovich, Chromatographia, 2000, 51, S217.

4. Z. Dincer, H. Basan, and N. G. Goger, J. Pharm. Biomed. Anal., 2003, 31, 867.

5. L. Colombo, F. Marcucci, M. G. Marini, P. Pierfederici, and E. Mussini, J. Chromatogr. Biomed. Appl., 1990, 53, 141.
6. B. T. Demircigil, B. Uslu, Y. Ozkan, S. A. Ozkan, and Z. Senturk, Electroanalysis, 2003, 15, 230.

7. M. Pospisilova, M. Polasek, and V. Jokl, J. Pharm. Biomed. Anal., 2001, 24, 421.

8. "Farmacopeia Portuguesa VII", ed. Oficial, 2002, Infarmed, Lisboa.

9. J. Ruzicka and E. H. Hansen, "Flow Injection Analysis". 2nd ed., 1988, Wiley Interscience, New York, 15.

10. J. Ruzicka and G. D. Marshall, Anal. Chim. Acta, 1990, $237,329$.

11. J. Ruzicka, Analyst, 2000, 125, 1053.

12. B. F. Reis, M. F. Giné, E. A. G. Zagatto, J. L. F. C. Lima, and R. A. S. Lapa, Anal. Chim. Acta, 1994, 293, 129.

13. R. A. S. Lapa, J. L. F. C. Lima, B. F. Reis, J. L. M. Santos, and E. A. G. Zagatto, Anal. Chim. Acta, 2002, 466, 125. 